\title{
A time-course microarray data analysis reveals consistent dysregulated genes and upstream microRNAs in autoantibody- mediated arthritis
}

\author{
Xinwen Wang ${ }^{1}$, Jie Bai ${ }^{1}$, Zhen Jia², Yangjun Zhu' ${ }^{1}$, Jijun Liu' ${ }^{1}$, Kun Zhang ${ }^{1}$, Dingjun Hao ${ }^{1}$ and Lisong Heng ${ }^{1 *}$
}

\begin{abstract}
Background: The purpose of this study is to identify key genes and microRNAs (miRNAs) involved in autoantibodymediated arthritis (AMA).

Methods: A time-course microarray data (ID: GSE27492) of peripheral blood leukocytes, ankle tissue, and synovial fluid from K/BxN mouse serum-transferred mice were downloaded from Gene Expression Omnibus. Those samples were collected at days $0,1,3,7,12$, and 18 after serum injection. Limma of $R$ was employed to identify differentially expressed genes (DEGs) in samples collected at days 1-18 compared with those collected at day 0. Consistent DEGs were obtained by taking the interaction of DEGs from different time points, followed by functional enrichment analysis. MiRNAs were screened out and constructed into regulatory network with DEGs using Cytoscape.
\end{abstract}

Results: In total, 17 consistent DEGs were obtained, including downregulated Ephx1 and upregulated AF251705, Adam8, Arg1, Basp1, CCl2, Ccl7, Cc19, Ccr2, Clec4a2, Clec4d, Cxcl1, Fabp5, Fcgr1, Gp49a, Il1rn, and Saa3. Those DEGs were associated with biological processes of immune response, inflammatory response, and defense response; chemokine signaling pathway; cytokine-cytokine receptor interaction; and NOD-like receptor signaling pathway. Additionally, 202 miRNAs were identified to have a regulatory effect on 9 of the 17 DEGs. Notably, miR-944, miR-374a, and miR374b were found to regulate the expression of $\mathrm{CxCl1}, \mathrm{Ccl} 7$, and $\mathrm{CCl}$. Clec4d was targeted by 78 miRNAs.

Conclusions: Our study reveals that 17 DEGs and 202 miRNAs may be associated with autoimmune disorder in the progression of AMA, which could guide future researches.

Keywords: Arthritis, Differentially expressed genes, MicroRNA, Regulatory network

\section{Background}

Rheumatoid arthritis (RA) is an autoimmune disease, which is characterized by inflammation of the joints and surrounding tissues and destruction of bone and cartilage [1]. Inflammatory response and immune response are found to play critical roles in the pathogenesis of RA [2-4]. Many cytokines have been implicated in the pathogenesis of arthritis, such as interleukin-1

\footnotetext{
* Correspondence: linchui444wenren@163.com

'Department of Orthopedics, Honghui Hospital, Xi'an Jiaotong University,

555 East Youyi Road, Xi'an 710054, Shaanxi, People's Republic of China

Full list of author information is available at the end of the article
}

(IL-1) [5], IL-6 [6], IL-18 [7], and CC motif chemokine ligand 13 [8]. Matrix metalloproteinases (MMPs) play key roles in the destructive process and thus are also implicated in arthritis [9], especially $M M P-1$ and $M M P-13$. Those uncovered genes demonstrate an involvement of the gene factor in the progression of arthritis.

Mouse models with autoantibody-mediated arthritis (AMA) are widely used in researches of arthritis [10]. The $\mathrm{K} / \mathrm{BxN}$ mouse model of arthritis is a common AMA mouse model, in which the upstream adaptive immune response involved in generation of arthritogenic 
autoantibodies can be easily separated from the downstream autoantibody-mediated effector phase [10]. Using this model, previous studies have demonstrated the involvement of immune response in the incidence of AMA. It is reported that mast cells contribute to the initiation of AMA via $I L-1$ [11]. Monach et al. indicated that circulating $\mathrm{C} 3$ was necessary and sufficient for induction of AMA [12]. Neutrophils also take parts in the development of AMA [13]. Follicular dendritic cells (FDCs) are important for the induction of protective $\mathrm{T}$ cell-dependent humoral responses, and thus, they play critical roles in the initiation of AMA [14]. Thus, the $\mathrm{K} / \mathrm{BxN}$ mouse serum transfer model could effectively help to reveal the underlying molecular mechanisms involved in the progression of AMA.

MicroRNAs (miRNAs) representing a family of noncoding RNAs are shown to play an essential regulatory effect on the innate immune system in rheumatic diseases [15]. MiRNA-30a-3p has a major regulatory role in regulating the autoimmune responses in arthritis by functioning as a basal repressor of tumor necrosis factor (ligand) superfamily, member 13b [16]. Inhibition of miR-155 can reversely increase the release of Src homology 2 domaincontaining inositol 5-phosphatase 1 and thus suppress inflammatory response in arthritis patients [17]. MiRNA22 exerts suppressive effect on cysteine-rich protein 61 expression which plays vital roles in mediating the joint inflammation and damage in arthritis [18]. Targeting the miRNAs associated with the progression of arthritis may serve as promising therapy strategies.

To systemically investigate the molecular mechanisms underlying AMA, the time-course gene expression profiles deposited by a previous study [10] were re-analyzed with bioinformatic tools. Consistent differentially expressed genes (DEGs) during the development of AMA in the $\mathrm{K} / \mathrm{BxN}$ mouse serum transfer model were identified, followed by enrichment analysis of DEGs in an attempt to explore the molecular mechanisms. MiRNAtargeting DEGs were also predicted in order to provide an insight into the regulatory network of DEGs.

\section{Methods}

\section{A time-course microarray data}

Microarray data set GSE27492 deposited by Jacobs et al. [10] was downloaded from Gene Expression Omnibus, including 17 peripheral blood leukocytes samples, 19 ankle tissue samples, and 13 synovial fluid samples. Synovial fluid cells were collected from articular cavity of dissected ankles, and ankle tissue cells were from the dissected ankle joints. All the samples were collected from a mouse model of AMA at six time points after arthritis induction: day 0 (baseline), day 1 (preclinical), day 3 (disease onset), day 7 (early disease), day 12 (disease plateau), and day 18 (late disease). Notably, an autoimmune response can develop in $\mathrm{K} / \mathrm{BxN}$ mice with the production of pathogenic anti-GPI antibodies which deposit on joint surfaces and induce arthritis [19]. Thus, AMA was induced in chemokine and chemokine receptor knockout mice on $\mathrm{B} 6$ background by intraperitoneal injection of $200 \mu \mathrm{L}$ of $\mathrm{K} / \mathrm{BxN}$ serum from 8-week-old $\mathrm{K} / \mathrm{BxN}$ mouse, and the mouse model of AMA was established. Affymetrix Murine Genome U74A Version 2 Array was used to collect the gene expression profiles of RNA extracted from the three groups of samples.

\section{Screening of differentially expressed genes}

Raw data were processed through background correction and median normalization using robust multiarray average method [20] from package Bioconductor of $R$. For the several probes corresponding to a single gene, their expression levels were averaged as the final expression level for the gene. Differential expression analysis was performed with package limma [21]. |log FC (fold change) $\mid>1$ and $P$ value $<0.05$ were set as the cut-offs to screen out DEGs. The expression levels of genes from samples collected at day $1,3,7,12$, and 18 were separately compared with those from samples collected at day 0 . The consistent DEGs were obtained for further analysis by taking the intersection of the DEGs emerging at all of the five time points.

\section{Functional enrichment analysis of the differentially expressed genes}

To identify altered biological pathways in arthritis, Gene Ontology (GO) enrichment analysis [22] and Kyoto Encyclopedia of Genes and Genomes (KEGG) pathway analysis [23] were carried out for the DEGs using hypergeometric test provided by DAVID (Database for Annotation, Visualization and Integration Discovery, http://david.abcc.ncifcrf.gov/) [24]. $P$ value $<0.05$ was chosen as the threshold to screen out significant GO terms and KEGG pathways.

\section{Construction of regulatory network between microRNAs and differentially expressed genes}

The miRNA-targeting DEGs were predicted based on 10 databases covering DIANA, MiRanda, MiRDB, MiRwalk, RNAhybrid, TargetScan, RNA22, PITA, PICTAR5, and PICTAR4. The predicted miRNAs from more than 5 of the 10 databases were identified as candidate miRNAs. Following, the regulatory network between miRNAs and DEGs was constructed using Cytoscape software [25].

\section{Results}

\section{Identification of DEGs}

Compared with the samples collected at day 0 after $\mathrm{K} / \mathrm{BxN}$ serum injection, a total of $0,35,103,62$, and75 DEGs were separately obtained from the samples collected at day 1,3 , 
7, 12, and 18. The Venn diagram of the DEGs from different time points was shown in Fig. 1. By taking the intersection of the DEGs from different time points, a total of 17 consistent DEGs were obtained, including downregulated Ephx1 (epoxide hydrolase 1, microsomal) and upregulated AF251705 (cDNA sequence AF251705), Adam8 (a disintegrin and metallopeptidase domain 8), Arg1 (arginase, liver), Basp1 (brain abundant, membrane attached signal protein 1$), \mathrm{Ccl} 2$ (chemokine (C-C motif) ligand 2), $\mathrm{Ccl}$ (chemokine (C-C motif) ligand 7), Ccl9 (chemokine (C-C motif) ligand 9), Ccr2 (chemokine (C-C motif) receptor 2), Clec4a2 (C-type lectin domain family 4 , member a2), Clec4d (C-type lectin domain family 4, member d), Cxcl1 (chemokine (C-X-C motif) ligand 1), Fabp5 (fatty acid binding protein 5, epidermal), Fcgr1 (Fc receptor, IgG, high affinity), Gp49a (glycoprotein 49 A), Il1rn (interleukin 1 receptor antagonist), and Saa3 (serum amyloid A 3) (Table 1).

\section{Functional enrichment analysis results}

With the cut-off of $P$ value $<0.05$, totally 14 significantly enriched GO terms and 3 KEGG pathways were obtained (Table 2). GO enrichment analysis revealed the DEGs were related to biological processes of immune response, inflammatory response, and defense response (e.g., Cxcl1, Ccl2, Ccr2, Fcgr1, and Ccl7), molecular functions of chemokine activity, chemokine receptor binding, and cytokine activity (e.g., Cxcl1, Ccl2, Ccl9, and Ccl7), as well as cellular components of extracellular space and extracellular region part (e.g., Cxcl1, Ccl2, Ccl9, and Ccl7). KEGG pathway enrichment analysis uncovered the DEGs were associated with chemokine signaling pathway (Cxcl1, Ccl2, Ccr2, Ccl9, and Ccl7), cytokinecytokine receptor interaction $(\mathrm{Cxcl} 1, \mathrm{Ccl} 2, \mathrm{Ccr} 2, \mathrm{Ccl} 9$,

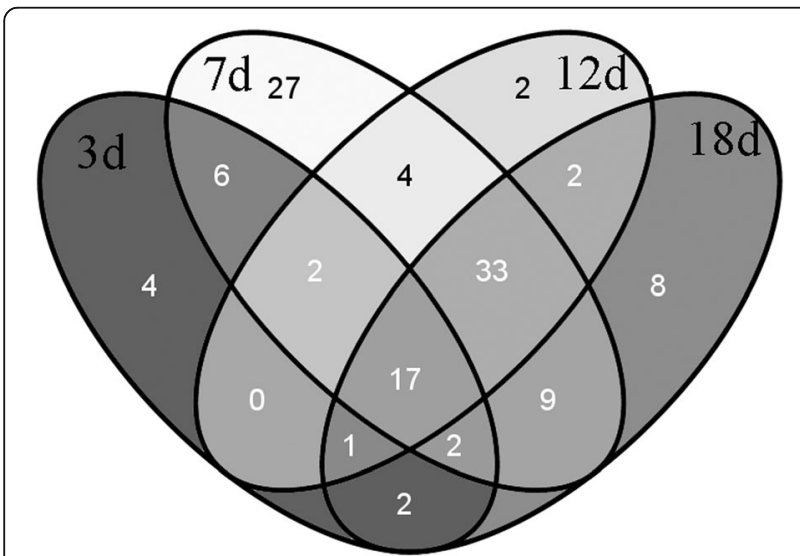

Fig. 1 The Venn diagram of the differentially expressed genes identified at various time points (days 3, 7, 12, and 18). Totally, 17 differentially expressed genes consistently appeared at each time point
Table 1 The FC magnitude of 17 consistent DEGs

\begin{tabular}{|c|c|c|c|c|}
\hline Gene & $\log _{2} F C \_3 d$ & $\log _{2} F C_{-} 7 d$ & $\log _{2} F C_{-} 12 d$ & $\log _{2} F C_{-} 18 d$ \\
\hline AF251705 & 1.305238 & 1.457843 & 1.423637 & 1.534935 \\
\hline Adam8 & 1.397521 & 1.545198 & 1.64087 & 1.397731 \\
\hline $\operatorname{Arg} 1$ & 3.216408 & 3.470759 & 3.253301 & 3.500893 \\
\hline Basp1 & 1.183961 & 1.402966 & 1.330427 & 1.417313 \\
\hline $\mathrm{CCl} 2$ & 3.136399 & 2.754264 & 2.608425 & 2.605791 \\
\hline $\mathrm{CCl} 7$ & 2.379615 & 1.747449 & 1.676018 & 1.364921 \\
\hline $\mathrm{CCl}$ & 1.592837 & 1.25133 & 1.348077 & 1.222959 \\
\hline $\mathrm{Ccr} 2$ & 1.395741 & 1.265384 & 1.07037 & 1.021065 \\
\hline Clec $4 a 2$ & 1.344762 & 1.371277 & 1.486593 & 1.286852 \\
\hline Clec $4 d$ & 2.328534 & 3.102078 & 3.12611 & 3.014611 \\
\hline Cxcl1 & 1.152963 & 2.378911 & 2.050006 & 2.15751 \\
\hline Ephx1 & -1.12827 & -1.5318 & -1.36148 & -1.05361 \\
\hline Fabp5 & 1.300109 & 1.492187 & 1.360936 & 1.174031 \\
\hline Fcgr1 & 1.565833 & 1.337319 & 1.266228 & 1.255231 \\
\hline Gp49a & 1.08629 & 1.48513 & 1.472467 & 1.684876 \\
\hline $117 r n$ & 2.356432 & 2.933974 & 2.905693 & 3.029609 \\
\hline $\mathrm{Saa3}$ & 2.536273 & 3.692907 & 3.451593 & 4.212274 \\
\hline
\end{tabular}

FC fold change; DEGs differentially expressed genes. Gene names: AF251705 CDNA sequence AF251705; Adam8 a disintegrin and metallopeptidase domain 8; Arg1 arginase, liver; Basp1 brain abundant, membrane attached signal protein $1 ; \mathrm{CCl} / 2$ chemokine ( $\mathrm{C}-\mathrm{C}$ motif) ligand $2 ; \mathrm{C} / 7$ chemokine ( $\mathrm{C}-\mathrm{C}$ motif) ligand 7; $\mathrm{CCl} 9$ chemokine ( $\mathrm{C}-\mathrm{C}$ motif) ligand $9 ; \mathrm{C} \mathrm{Cr} 2$ chemokine ( $\mathrm{C}-\mathrm{C}$ motif) receptor 2; Clec4a2 C-type lectin domain family 4, member a2; Clec4d C-type lectin domain family 4, member $\mathrm{d}$; $\mathrm{CxCl1}$ chemokine (C-X-C motif) ligand 1; Ephx 1 epoxide hydrolase 1, microsomal; Fabp5 fatty acid binding protein 5, epidermal; Fcgr1 Fc receptor, IgG, high affinity; Gp49a glycoprotein 49 A; I11rn interleukin 1 receptor antagonist; Saa3 serum amyloid A 3

and $C c l 7$ ), and NOD-like receptor signaling pathway (Cxcl1, Ccl2, and Ccl7).

\section{Regulatory network between microRNAs and differentially expressed genes}

Using the 10 databases for predicting miRNAs, 202 persuasive miRNAs were identified to have a regulatory effect on 9 of the 17 DEGs, including miR-155, miR-152, miR-124, miR-1, and miR-206 (Fig. 2). Importantly, according to the network, miR-944 was found to have a regulatory effect on the expression of $\mathrm{Cxcl1}$ and $\mathrm{Ccl} 7$; miR-374a and miR374b both could regulate the expression of $\mathrm{Ccl} 7$ and $\mathrm{Ccl} 2$. Additionally, Clec4d was targeted by 78 miRNAs, suggesting an important role in the regulatory network.

\section{Discussion}

Focusing on screening molecular targets for AMA therapy, this study obtained 16 up-regulated and 1 downregulated genes in the mouse with AMA compared with the mouse without AMA by re-analyzing the timecourse microarray data. Large troop of miRNAs was also screened to have a regulatory effect on 9 of the 17 DEGs based on the predictive databases. Enrichment analysis 
Table 2 The significantly enriched GO and KEGG terms of the 17 DEGs

\begin{tabular}{|c|c|c|c|}
\hline Term & Number & $P$ value & Gene lists \\
\hline \multicolumn{4}{|l|}{ GO term } \\
\hline GO_BP: immune response & 11 & $5.86 \mathrm{E}-12$ & Cxcl1, Ccl2, Gp49a, Ccr2, II1rn, Ccl9, Clec4a2, AF251705, Clec4d, Fcgr1, Ccl) \\
\hline GO_BP: response to wounding & 7 & $1.09 \mathrm{E}-06$ & Cxcl1, Arg1, Ccl2, Ccr2, Saa3, Fcgr1, Ccl7 \\
\hline GO_BP: inflammatory response & 6 & $3.12 \mathrm{E}-06$ & $\mathrm{Cxcl1}, \mathrm{Ccl} 2, \mathrm{Ccr} 2, \mathrm{Saa3}$, Fcgr1, Ccl7 \\
\hline GO_MF: chemokine activity & 4 & 4.66E-06 & $\mathrm{CxCl}, \mathrm{Ccl} 2, \mathrm{Ccl} 9, \mathrm{Ccl} 7$ \\
\hline GO_MF: chemokine receptor binding & 4 & 5.05E-06 & $\mathrm{CxCl}, \mathrm{Ccl} 2, \mathrm{Cc} 19, \mathrm{Ccl} 7$ \\
\hline GO_CC: extracellular space & 7 & $1.65 \mathrm{E}-05$ & Cxcl1, $\operatorname{Arg} 1, \mathrm{Ccl} 2,111 \mathrm{rn}, \mathrm{Saa} 3, \mathrm{Ccl}, \mathrm{Ccl} 7$ \\
\hline GO_BP: defense response & 6 & $8.70 \mathrm{E}-05$ & $\mathrm{CxCl}$, Ccl2, Ccr2, Saa3, Fcgr1, Ccl7 \\
\hline GO_CC: extracellular region part & 7 & 1.70E-04 & $\mathrm{CxCl1}, \operatorname{Arg} 1, \mathrm{Ccl} 2,111 \mathrm{~m}, \mathrm{Saa} 3, \mathrm{Ccl} 9, \mathrm{Ccl} 7$ \\
\hline GO_MF: cytokine activity & 4 & $4.92 \mathrm{E}-04$ & $\mathrm{CxCl}, \mathrm{Ccl} 2, \mathrm{Cc} 19, \mathrm{Ccl} 7$ \\
\hline GO_BP: chemotaxis & 3 & $6.25 \mathrm{E}-03$ & $\mathrm{Ccl} 2, \mathrm{Cc} 19, \mathrm{Ccl} 7$ \\
\hline GO_BP: taxis & 3 & $6.25 \mathrm{E}-03$ & $\mathrm{Ccl} 2, \mathrm{Cc} 19, \mathrm{Ccl} 7$ \\
\hline GO_CC: extracellular region & 7 & $9.88 \mathrm{E}-03$ & $\mathrm{CxCl1}, \operatorname{Arg} 1, \mathrm{Ccl} 2,111 \mathrm{~m}, \mathrm{Saa} 3, \mathrm{Ccl} 9, \mathrm{Ccl} 7$ \\
\hline GO_BP: locomotory behavior & 3 & $2.78 \mathrm{E}-02$ & $\mathrm{Ccl} 2, \mathrm{Cc} 19, \mathrm{Ccl} 7$ \\
\hline GO_MF: carbohydrate binding & 3 & $3.20 \mathrm{E}-02$ & Clec4a2, Clec4d, Ccl7 \\
\hline \multicolumn{4}{|l|}{ KEGG pathway } \\
\hline mmu04062:chemokine signaling pathway & 5 & $6.21 \mathrm{E}-05$ & $\mathrm{CxCl}, \mathrm{Ccl} 2, \mathrm{Ccr} 2, \mathrm{Ccl} 9, \mathrm{Ccl} 7$ \\
\hline mmu04060:cytokine-cytokine receptor interaction & 5 & $1.95 \mathrm{E}-04$ & $\mathrm{CxCl} 1, \mathrm{Ccl} 2, \mathrm{Ccr} 2, \mathrm{Cc} 19, \mathrm{Ccl} 7$ \\
\hline mmu04621:NOD-like receptor signaling pathway & 3 & $3.08 \mathrm{E}-03$ & $\mathrm{CxCl}, \mathrm{Ccl} 2, \mathrm{Ccl} 7$ \\
\hline
\end{tabular}

GO Gene Ontology, KEGG Kyoto Encyclopedia of Genes and Genomes; DEGs differentially expressed genes; $B P$ biological process; $M F$ molecular function; CC cellular component. Gene names: AF251705 cDNA sequence AF251705; Arg1 arginase, liver; Ccl2 chemokine (C-C motif) ligand 2; Ccl7 chemokine (C-C motif) ligand 7; C Cl9 chemokine (C-C motif) ligand 9; $\mathrm{Ccr} 2$ chemokine (C-C motif) receptor 2; Clec4a2 C-type lectin domain family 4, member a2; Clec4d C-type lectin domain family 4, member d; Cxcl1 chemokine (C-X-C motif) ligand 1; Fcgr1 Fc receptor, IgG, high affinity; Gp49a glycoprotein 49 A; II1rn interleukin 1 receptor antagonist; Saa3 serum amyloid $\mathrm{A} 3$

unmasked the potential molecular mechanisms by which the DEGs take part in the development of AMA.

Chemokines consisting of $\mathrm{CXC}, \mathrm{CC}, \mathrm{C}$, and $\mathrm{CX}_{3} \mathrm{C}$ groups and their receptors are revealed to play key roles in leukocyte migration to inflamed synovium in the treatment of chronic inflammatory disorders of RA [26]. Accordingly, this study revealed a number of dysregulated chemokines and their receptors in the development of AMA, such as Adam8, Saa3, Illrn, Ccl2, Ccl7, Ccl9, Ccr2, and Cxcl1. GO enrichment analysis revealed that immune response and inflammatory response were significantly enriched biological processes of DEGs, which were linked to RA and in line with previous studies [2-4, 27]. Those biological processes-associated genes, such as Cxcl1, Ccl2, Ccr2, Fcgr1, and Ccl7 were also associated with molecular functions of chemokine activity, chemokine receptor binding, and cytokine activity. Thus, a disorder of chemokine-associated functions was also observed in this study. In addition, Adam8 is detected under several pathological conditions and may be a potential drug target for the treatment of inflammatory diseases [28]. IL-33-induced neutrophil migration in RA is found to be dependent on Cxcl1, which may be a target of antiTNF therapy [29]. CCR2 is regarded as a therapeutic target in RA treatment [30]. These findings suggest that some chemokines and receptors as therapeutic targets may have feasibility and application prospects in RA therapy. However, the CCR2 blockade cannot sufficiently induce clinical improvement in RA patients [31].The antiCCL2 monoclonal antibody treatment also results in poor clinical improvement [32]. It could be inferred that the chronic inflammatory disorder may not only result from multiple dysregulated chemokines and receptors but also result from some other immune-associated genes; thus, targeting single molecule may not improve and cure the disease. Further studies are still needed to confirm the clinical feasibility and application prospects of these dysregulated chemokines and their receptors in RA therapy. Furthermore, as previously demonstrated, Fcgr 1 makes a contribution to arthritis pathology [33]; Clec4a2 and Clec4d play essential roles in maintaining the homeostasis of immune system [34, 35]; Arg1 activity is important for wound healing functions and immune response to viral infections [36]. Therefore, the uncovered 17 dysregulated genes may jointly contribute to the chronic inflammatory disorder and need an integrated regulation.

Correspondingly, KEGG pathway enrichment analysis revealed the DEGs were associated with chemokine signaling pathway, cytokine-cytokine receptor interaction, and NOD-like receptor signaling pathway. Those 


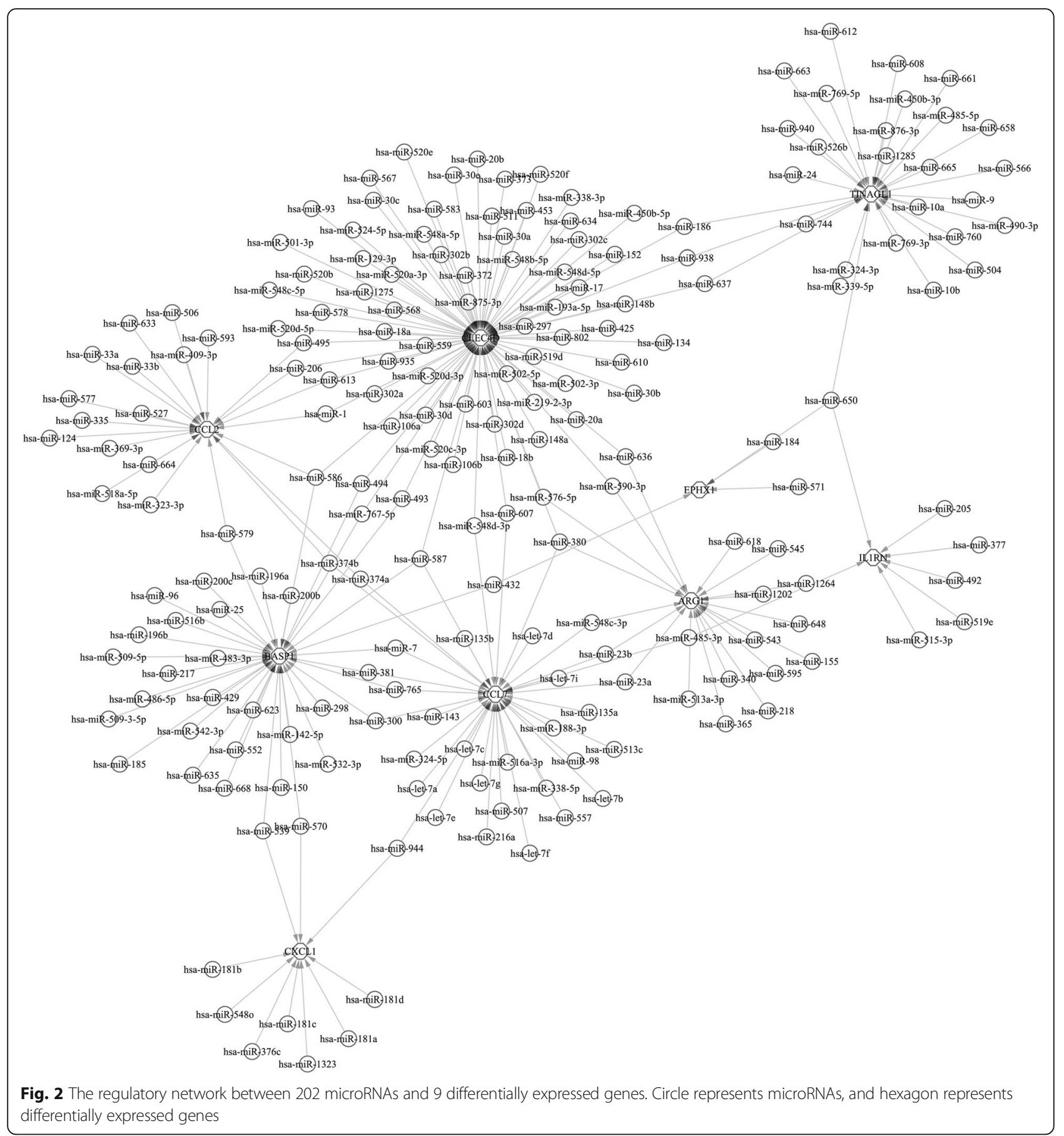

pathways are closely related to inflammatory and immune responses. The upregulation of chemokine receptors $C c r 1, C c r 2$, and $C c r 5$ are associated with macrophage and endothelial cell infiltration in arthritis [37]. The cytokine-cytokine receptor interaction is also revealed to be implicated in the progression of RA [38]. The nucleotide-binding oligomerization domain (NOD)-like receptors are a class of specialized intracellular receptors implicated in the innate immune system [39]. The
NOD2 signaling could be used as a therapeutic target for the control of RA [40]. Mesothelial cells involved in the inflammatory responses could secret chemokines Cxcl1 and Ccl 2 by Nod1 stimulation [41]. Considering the possible role of these pathways in regulating inflammatory and immune response, these specific pathways may provide a new insight for therapeutics of other autoimmune disorders, such as periodental infection (bacterial), urinary tract infection (bacterial), and psoriatic 
arthropathy. More studies are still needed to confirm our speculation.

Furthermore, a large cohort of miRNAs was identified to be associated with the DEGs and the miRNAs were constructed into a regulatory network with DEGs. MiR155, miR-152, and miR-124 have been shown to be implicated in RA [42-44]. MiR-1 and miR-206 are also associated with inflammation [45]. They were all contained in our regulatory network, suggesting the reliability of our network to some extent. Additionally and importantly, based on the network, miR-944, miR-374a, and miR374b were revealed to have a regulatory effect on the expression of Cxcl1, Ccl2, and Ccl7. MiR-944 located in the intron of TP63 gene could promote cell proliferation, migration, and invasion in human cervical cancer [46]. MiR-374 experiences dysregulation in the inflammatory mice [47]. Although there are no direct links between those two miRNAs with immune systems, based on our results, miRNA-944 and miR-374 were predicted to be involved in the AMA via targeting Cxcl1, Ccl2, and Ccl7. Additionally, Clec4d was targeted by 78 miRNAs. Previous report has pointed out activated Clec4d can contribute to Mincel expression and thus enhance the immune system [35]. It could be therefore speculated that Clec4d may play a role in AMA as a downstream target of various miRNAs. Although the role of the above miRNAs and Clec4d in RA development has not been fully investigated, based on our results, we speculate that these molecules may serve as potential targets for RA treatment. All these speculations need further research. There were some limitations in our study. The comparative studies of other arthritis models were not included this study. Moreover, the results were obtained based on the bioinformatic methods and should be further confirmed by mechanistic experiments. Even so, this study reveals 17 DEGs associated with AMA, which may provide a theoretical basis for further studies.

\section{Conclusion}

Focusing on screening of therapeutic targets for AMA, this study reveals that 17 dysregulated genes may jointly and consistently play roles in the progression of AMA by affecting the immune system functions and pathways. MiR-944, miR-374a, and miR374b may be associated with AMA development by targeting some chemokines. Also, Clec4d probably mediates the functions of a large number of miRNAs in the development of AMA. Further experiments, both epidemiological and mechanical, should be performed to confirm the results.

\section{Abbreviations}

AMA: Autoantibody-mediated arthritis; DEGs: Differentially expressed genes; FDCs: Follicular dendritic cells; GO: Gene Ontology; KEGG: Kyoto
Encyclopedia of Genes and Genomes; miRNAs: MicroRNAs; NOD: Nucleotidebinding oligomerization domain; RA: Rheumatoid arthritis

\section{Acknowledgements}

None.

\section{Funding}

This work was supported by Science and Technology Project of Shaanxi Social Development (Project number: 2016SF-223).

\section{Availability of data and materials}

Microarray data set GSE27492 deposited by Jacobs et al. was downloaded from Gene Expression Omnibus.

\section{Authors' contributions}

$\mathrm{XW}$ and $\mathrm{LH}$ participated in the conception and design of the research. $J B, Z J$, and DH conceived of the data acquisition; $Y Z, J L$, and DH participated in the analysis and interpretation of data. JB and $\mathrm{KZ}$ conceived of the statistical analysis. YZ obtained the funding. LH drafted the manuscript. XW conceived of the revision of the manuscript for important intellectual content. All authors read and approved the final manuscript.

Ethics approval and consent to participate

This article does not contain any studies with human participants or animals performed by any of the authors. The ethics approval is unnecessary for our study.

\section{Consent for publication}

Not applicable.

\section{Competing interests}

The authors declare that they have no competing interests.

\section{Publisher's Note}

Springer Nature remains neutral with regard to jurisdictional claims in published maps and institutional affiliations.

\section{Author details}

'Department of Orthopedics, Honghui Hospital, Xi'an Jiaotong University, 555 East Youyi Road, Xi'an 710054, Shaanxi, People's Republic of China. 2Department of Endocrinology, Xi'an No. 1 Hospital, Xi'an 710002, Shaanxi, People's Republic of China.

Received: 2 March 2017 Accepted: 3 November 2017

Published online: 02 December 2017

References

1. Seeling M, Hillenhoff U, David JP, Schett G, Tuckermann J, Lux A, et al. Inflammatory monocytes and Fcy receptor IV on osteoclasts are critical for bone destruction during inflammatory arthritis in mice. Proc Natl Acad Sci. 2013;110(26):10729-34

2. Firestein GS. Immunologic mechanisms in the pathogenesis of rheumatoid arthritis. JCR: Journal of Clinical Rheumatology. 2005;11(3):S39-44.

3. McInnes IB, Schett $G$. Cytokines in the pathogenesis of rheumatoid arthritis. Nat Rev Immunol. 2007;7(6):429-42.

4. Mclnnes IB, Schett $G$. The pathogenesis of rheumatoid arthritis. N Engl J Med. 2011:365(23):2205-19.

5. Pascual V, Allantaz F, Arce E, Punaro M, Banchereau J. Role of interleukin-1 $(\mathrm{IL}-1)$ in the pathogenesis of systemic onset juvenile idiopathic arthritis and clinical response to IL-1 blockade. J Exp Med. 2005;201(9):1479-86.

6. Park JY, Pillinger MH. Interleukin-6 in the pathogenesis of rheumatoid arthritis. Bulletin of the NYU hospital for joint diseases. 2006;65:54-10.

7. Volin MV, Koch AE. Interleukin-18: a mediator of inflammation and angiogenesis in rheumatoid arthritis. J Interf Cytokine Res. 2011;31(10):745-51.

8. Yamaguchi A, Nozawa K, Fujishiro M, Kawasaki M, Suzuki F, Takamori K, et al. CC motif chemokine ligand 13 is associated with rheumatoid arthritis pathogenesis. Mod Rheumatol. 2013;23(5):856-63.

9. Burrage PS, Mix KS, Brinckerhoff CE. Matrix metalloproteinases: role in arthritis. Front Biosci. 2006;11(1):529-43. 
10. Jacobs JP, Ortiz-Lopez A, Campbell JJ, Gerard CJ, Mathis D, Benoist C. Deficiency of CXCR2, but not other chemokine receptors, attenuates autoantibody-mediated arthritis in a murine model. Arthritis \& Rheumatism. 2010;62(7):1921-32.

11. Nigrovic PA, Binstadt BA, Monach PA, Johnsen A, Gurish M, Iwakura Y, et al. Mast cells contribute to initiation of autoantibody-mediated arthritis via IL-1. Proc Natl Acad Sci. 2007;104(7):2325-30.

12. Monach PA, Verschoor A, Jacobs JP, Carroll MC, Wagers AJ, Benoist C et al. Circulating $C 3$ is necessary and sufficient for induction of autoantibodyia IL-1. Proceedings in a mouse model. Arthritis \& Rheumatism. 2007;56(9):2968-2974.

13. Monach PA, Nigrovic PA, Chen M, Hock H, Lee DM, Benoist C, et al. Neutrophils in a mouse model of autoantibody-mediated arthritis: critical producers of Fc receptor $\gamma$, the receptor for C5a, and lymphocyte functionassociated antigen 1. Arthritis \& Rheumatism. 2010;62(3):753-64.

14. Victoratos P, Kollias G. Induction of autoantibody-mediated spontaneous arthritis critically depends on follicular dendritic cells. Immunity. 2009; 30(1):130-42.

15. Luo X, Ranade K, Talker R, Jallal B, Shen N, Yao Y. microRNA-mediated regulation of innate immune response in rheumatic diseases. Arthritis research \& therapy. 2013;15(2):210. https://doi.org/10.1186/ar4194.

16. Alsaleh G, Francois A, Philippe L, Gong YZ, Bahram S, Cetin S, et al. MiR$30 a-3 p$ negatively regulates BAFF synthesis in systemic sclerosis and rheumatoid arthritis fibroblasts. PLoS One. 2014;9(10):e111266. doi:10. 1371/journal.pone.0111266.

17. Peng A, Huang X, Liu R, Wang X, Zhuang J. Triptolide inhibits the inflammatory response of monocytes from rheumatoid arthritis patients by regulating miR-155. Xi bao yu fen zi mian yi xue za zhi $=$ Chinese journal of cellular and molecular immunology. 2014;30(6):635-8.

18. Lin J, Huo R, Xiao L, Zhu X, Xie J, Sun S, et al. A novel p53/microRNA22/Cyr61 axis in synovial cells regulates inflammation in rheumatoid arthritis. Arthritis \& rheumatology (Hoboken, NJ). 2014;66(1):49-59. doi:10.1002/art.38142.

19. Ji H, Ohmura K, Mahmood U, Lee DM, Hofhuis FM, Boackle SA, et al. Arthritis critically dependent on innate immune system players. Immunity. 2002;16(2):157-68.

20. Irizarry RA, Hobbs B, Collin F, Beazer-Barclay YD, Antonellis KJ, Scherf U, et al. Exploration, normalization, and summaries of high density oligonucleotide array probe level data. Biostatistics. 2003:4(2):249-64. doi:10.1093/ biostatistics/4.2.249.

21. Smyth GK. Limma: linear models for microarray data. Bioinformatics and computational biology solutions using $\mathrm{R}$ and Bioconductor. New York: Springer; 2005. p. 397-420.

22. Ashburner M, Ball CA, Blake JA, Botstein D, Butler H, Cherry JM, et al. Gene ontology: tool for the unification of biology. Nat Genet. 2000;25(1):25-9.

23. Kanehisa M, Goto S. KEGG: kyoto encyclopedia of genes and genomes. Nucleic Acids Res. 2000;28(1):27-30.

24. Sherman BT, Huang d W, Tan Q, Guo Y, Bour S, Liu D, et al. DAVID Knowledgebase: a gene-centered database integrating heterogeneous gene annotation resources to facilitate high-throughput gene functional analysis. BMC Bioinformatics. 2007;8:426. doi:10.1186/1471-2105-8-426.

25. Kohl M, Wiese S, Warscheid B. Cytoscape: software for visualization and analysis of biological newtworks. Data mining in proteomics. New York: Springer; 2011. p. 291-303.

26. Koch AE. Chemokines and their receptors in rheumatoid arthritis: future targets? Arthritis Rheum. 2005:52(3):710-21. doi:10.1002/art.20932.

27. Cassell S, Kavanaugh A. Psoriatic arthritis: pathogenesis and novel immunomodulatory approaches to treatment. Journal of immune based therapies and vaccines. 2005;3(1):6.

28. Koller G, Schlomann U, Golfi P, Ferdous T, Naus S, Bartsch JW. ADAM8/MS2/ CD156, an emerging drug target in the treatment of inflammatory and invasive pathologies. Curr Pharm Des. 2009;15(20):2272-81.

29. Verri WA, Souto FO, Vieira SM, Almeida SC, Fukada SY, Xu D, et al. IL-33 induces neutrophil migration in rheumatoid arthritis and is a target of antiTNF therapy. Ann Rheum Dis. 2010;69(9):1697-703.

30. Quinones MP, Estrada CA, Kalkonde Y, Ahuja SK, Kuziel WA, Mack M, et al. The complex role of the chemokine receptor CCR2 in collagen-induced arthritis: implications for therapeutic targeting of CCR2 in rheumatoid arthritis. Journal of molecular medicine (Berlin, Germany). 2005;83(9):672-81. doi:10.1007/s00109-005-0637-5.

31. Vergunst CE, Gerlag DM, Lopatinskaya L, Klareskog L, Smith MD, van den Bosch F, et al. Modulation of CCR2 in rheumatoid arthritis: a double-blind, randomized, placebo-controlled clinical trial. Arthritis Rheum. 2008;58(7): 1931-9. doi:10.1002/art.23591.

32. Haringman JJ, Gerlag DM, Smeets TJ, Baeten D, van den Bosch F, Bresnihan B, et al. A randomized controlled trial with an anti-CCL2 (anti-monocyte chemotactic protein 1) monoclonal antibody in patients with rheumatoid arthritis. Arthritis Rheum. 2006;54(8):2387-92. doi:10.1002/art.21975.

33. Boross $\mathrm{P}$, van Lent $\mathrm{PL}$, Martin-Ramirez J, van der Kaa J, Mulder $\mathbf{M H}$ Claassens JW, et al. Destructive arthritis in the absence of both FcgammaRI and FcgammaRIII. Journal of immunology (Baltimore Md : 1950). 2008;180(7):5083-91.

34. Fujikado N, Saijo S, Yonezawa T, Shimamori K, Ishii A, Sugai S, et al. Dcir deficiency causes development of autoimmune diseases in mice due to excess expansion of dendritic cells. Nat Med. 2008;14(2):176-80. doi:10.1038/nm1697.

35. Zhao XQ, Zhu LL, Chang Q, Jiang C, You Y, Luo T, et al. C-type lectin receptor dectin-3 mediates trehalose 6,6'-dimycolate (TDM)-induced Mincle expression through CARD9/BCl10/MALT1-dependent nuclear factor (NF)kappaB activation. J Biol Chem. 2014;289(43):30052-62. doi:10.1074/jbc. M114.588574.

36. Burrack KS, Morrison TE. The role of myeloid cell activation and arginine metabolism in the pathogenesis of virus-induced diseases. Front Immunol. 2014:5:428. doi:10.3389/fimmu.2014.00428.

37. Shahrara S, Amin MA, Woods JM, Haines GK, Koch AE. Chemokine receptor expression and in vivo signaling pathways in the joints of rats with adjuvant-induced arthritis. Arthritis Rheum. 2003;48(12):3568-83. doi:10.1002/art.11344.

38. Liu G, Jiang Y, Chen X, Zhang R, Ma G, Feng R, et al. Measles contributes to rheumatoid arthritis: evidence from pathway and network analyses of genome-wide association studies. PLoS One. 2013;8(10):e75951. doi:10.1371/journal.pone.0075951.

39. Chen G, Shaw MH, Kim YG, Nunez G. NOD-like receptors: role in innate immunity and inflammatory disease. Annu Rev Pathol. 2009;4:365-98. doi:10.1146/annurev.pathol.4.110807.092239.

40. Vieira SM, Cunha TM, Franca RF, Pinto LG, Talbot J, Turato WM et al. Joint NOD2/RIPK2 signaling regulates IL-17 axis and contributes to the development of experimental arthritis. Journal of immunology (Baltimore, Md : 1950). 2012; 188(10):5116-5122. doi:10.4049/jimmunol.1004190.

41. Park JH, Kim YG, Shaw M, Kanneganti TD, Fujimoto Y, Fukase K et al. Nod1/ RICK and TLR signaling regulate chemokine and antimicrobial innate immune responses in mesothelial cells, Journal of immunology (Baltimore Md : 1950) 2007;179(1):514-521.

42. Miao CG, Yang YY, He X, Huang C, Huang Y, Qin D, et al. MicroRNA-152 modulates the canonical Wnt pathway activation by targeting DNA methyltransferase 1 in arthritic rat model. Biochimie. 2014; doi:10.1016/j. biochi.2014.08.016.

43. Zhou Q, Haupt S, Kreuzer JT, Hammitzsch A, Proft F, Neumann C, et al. Decreased expression of miR-146a and miR-155 contributes to an abnormal Treg phenotype in patients with rheumatoid arthritis. Ann Rheum Dis. 2014; doi:10.1136/annrheumdis-2013-204377.

44. Zhou Q, Long L, Shi G, Zhang J, Wu T, Zhou B. Research of the methylation status of miR-124a gene promoter among rheumatoid arthritis patients. Clinical \& developmental immunology. 2013;2013: 524204. doi:10.1155/2013/524204

45. Georgantas RW, Streicher K, Greenberg SA, Greenlees L, Zhu W, Brohawn P, et al. Inhibition of myogenic MicroRNAs-1, 133, and 206 by inflammatory cytokines links inflammation and muscle degeneration in adult inflammatory myopathies. Arthritis Rheum. 2013; doi:10.1002/art.38292.

46. Xie H, Lee L, Scicluna P, Kavak E, Larsson C, Sandberg R, et al. Novel functions and targets of miR-944 in human cervical cancer cells. International journal of cancer Journal international du cancer. 2014; doi:10.1002/ijc.29160.

47. Delic D, Dkhil M, Al-Quraishy S, Wunderlich F. Hepatic miRNA expression reprogrammed by Plasmodium chabaudi malaria. Parasitol Res. 2011;108(5): 1111-21. doi:10.1007/s00436-010-2152-z. 